\title{
Exploration Analysis of Some Panel Data Estimators in the Presence of One-Sided Exponential Heteroscedasticity Structure
}

\author{
Ayoola Femi Joshua \\ Department of Statistics, University of Ibadan, Ibadan, Nigeria \\ Email address: \\ fj.ayoola@ui.edu.ng, ayoolafemi@yahoo.com
}

To cite this article:

Ayoola Femi Joshua. Exploration Analysis of Some Panel Data Estimators in the Presence of One-Sided Exponential Heteroscedasticity Structure. American Journal of Theoretical and Applied Statistics. Vol. 6, No. 5, 2017, pp. 248-253. doi: 10.11648/j.ajtas.20170605.14

Received: May 18, 2017; Accepted: June 12, 2017; Published: September 18, 2017

\begin{abstract}
This paper aimed at assessing the performance of some estimators in the presence of one-sided exponential heteroscedasticity structure in panel model estimation. This study employs Monte Carlo experiments to evaluate the performances. It focuses on random effects models with 150 and 300 as cross-sectional units $(\mathrm{N})$ and 10 and 20 as time periods (T) with Absolute Bias (ABIAS) and Root Mean Squared Error (RMSE) were criterion for assessing the performances of the estimators. The estimators were then ordered according to their performances. Generally, the performance improved as the combinations of $\mathrm{N}$ and $\mathrm{T}$ increased in experiments. The ranking of the eight estimators for the experiment are in the order: PGLS (95\%), SWAR (69\%), NER (64\%), WG (45\%), AM (43\%), WALHUS (37\%), BG (36\%) and POLS (28\%). Panel generalised least squares estimator (PGLS) outperformed other estimators in the presence of OEHS, using POLS as a known benchmark to gauge the performance and the work will help in the choice of estimators when faced with empirical datasets that exhibit exponential heteroscedasticity.
\end{abstract}

Keywords: Panel Data, Estimators, Monte Carlo Simulation, One-Sided Exponential Heteroscedasticity, Performance

\section{Introduction}

Panel data and longitudinal models have become progressively widespread among applied researchers due to their heightened capacity for capturing the complexity of human behaviour unlike cross-sectional or time series data models [1]. Despite these advantages, panel data are subject to their own experimental problems. Prominent among the problems constantly addressed in panel data econometrics are selectivity and heterogeneity biases.

Although assuming homoscedastic disturbances when heteroscedasticity is present will still result in unbiased and consistent estimates of the regression coefficients, these estimates will not be efficient [2]. This, however, may be a restrictive assumption. When one begins to look at a crosssection of regions, states, countries, etc., these aggregate units may exhibit a cross-sectional correlation that has to be dealt with [3].

Both theoretical and applied econometricians have constantly been tackling these econometric problems in panel econometrics. Prominent among these studies include [4], [5], [6]. [7], [8], [9] and [10].

As largely acknowledged, heteroscedasticity is endemic when working with microeconomic cross-section data. Basically, heteroscedasticity may be viewed as symptom arising from the fact that the degree to which an economic relationship may explain actual individual observations is likely to depend on their specific characteristics.

Obviously, there is no reason to expect the heteroscedasticity problems associated with microeconomic panel data to be markedly different from those encountered in work with cross-section data. Nonetheless, the issue of heteroscedasticity received somewhat less attention in the literature related to panel data error components models than in the literature related to cross-section models.

The present study, therefore, addresses the drawback in these studies by introducing one-sided exponential heteroscedasticity structure (OEHS) on only individual specific effect error term to estimate and rank the performances of eight purposely chosen estimators in a one- 
way random error component model.

This paper is structured as follow: Section 2 presents the theoretical framework. Section 3 describes data the data generating scheme. Section 4 presents results and discussion while the last section concludes the paper.

\section{Review of Some Related Studies}

A primary and well-known source of heteroscedasticity stems from differences in the size characteristic of the observations. This kind of heteroscedasticity is purely mechanical. It is simply a consequence of the assumed additive disturbance structure of the classical regression model. It is generally tackled by performing a logarithmic transformation of the dependent variable.

[4] seem to be the first to deal with the problem of heteroscedasticity in panel data. The study looked at heteroscedasticity and stratification in two-way error component models. The study involved spectral decomposition of the variance-covariance matrix in deriving statistically efficient and computationally simple estimation procedures.

The early literature on one-way error components models includes [11] and [12] who allowed for lagged dependent variables, but [13] who compared eleven estimators, including Maximum Likelihood (ML). [14] considered the use of a three-way error components linear regression model and developed an Aitken estimator of the coefficient vector based on an estimated variance-covariance matrix. Their paper was extended by [15], [16] and [17]. [18] tried to check the sensitivity of two adaptive heteroscedastic estimators suggested by [10] and [19] for an error component regression model to misspecification of the form of heteroscedasticity. In particular, they run Monte Carlo experiments using the heteroscedasticity set up by [10] to see how the misspecified [19] estimator performs. [18] also patterned the sensitivity of these results to the choice of the smoothing parameters, the sample size, and the degree of heteroscedasticity. They found that the [10] estimator performs better under this type of misspecification than the corresponding estimator of [19]. They, however, suggested that the former estimator is sensitive to the choice of the bandwidth.

More recent applications include the work of [20] who studied the production behaviour of 1147 sawmills in the state of Washington, observed biennially over the period 1972-1984, [21], who estimated the effect of per capita income on the calorie intake using the panel data collected by the International Crops Research Institute for Semi-Arid Tropics Village level studies in rural South India.

In the presence of both autocorrelation and heteroscedasticity, the usual OLS estimators, although linear, unbiased, and asymptotically normally distributed, are no longer having minimum variance among all linear unbiased estimators. [22] and [23]. Thus, the OLS estimator is not efficient relative to other linear and unbiased estimators under such situations. A number of works on the methodologies and applications of panel data modelling have appeared in the literature ([10], [22],[23], [24] and [29]).

Situations, where all the necessary assumptions underlying the use of classical linear regression methods are satisfied, are rarely found in real life situations. Most of the studies that discussed panel data modelling considered the violation of each of the classical assumptions separately. Others [25], who estimated a production function for ambulatory care using panel data on 30 health care centres in New-York state over the period 1984-1987, [26], who used the PISD to study the sensitivity of male labour supply function estimates to how the wage is measured and how the researcher models individual heterogeneity, [27], who used panel data from the NSLY to show that much of the wage premium normally attributed to marriage is associated with individual unobservable individual effects that are correlated with marital status and wages.

\section{Methodology and Model Specification}

A distinctive static panel data regression can be expressed as:

$$
Y_{i t}=\beta_{o}+\sum_{k=1}^{j} \beta_{k} X_{k i t}+u_{i t} ; \quad i=1, \ldots, N, \quad t=1, \ldots, T
$$

where $Y_{i t}$ is the dependent variable and $X_{k i t}$ are the matrix of explanatory variables. The subscripts $i$ and $t$ as earlier defined refer to cross-sectional and time series dimensions respectively. $u_{i t}$ is the composite error term which can be decomposed further into specific effects and remainder disturbance term. For this paper, we shall limit our empirical applications to the one-way error components as stated below.

$$
u_{i t}=\mu_{i}+v_{i t}
$$

where

$y_{i t}$ is the dependent variable,

$x_{i t}$ is $(1 \times k)$ a vector of explanatory variable

$\beta_{k}$ is $(k \times 1)$ a vector of coefficients

$\mu_{i}$ represents unobserved cross-sectional (individual) effects for $N$ cross sections,

$v_{i t}$ represents remainder disturbance term.

\subsection{Theoretical Framework on Heteroscedasticity}

The index $i$ refers to the individuals and the index $t$ to the observations of each individual. The total number of observations is $N T$. In this work, we are going to consider OEHS is incorporated on the individual effect. The error terms $\mu_{i}$ and $v_{i t}$ are assumed mutually independent and normally distributed according to:

$$
\mu_{i} \sim N\left(0, \omega_{i}^{2}\right) \text { and } v_{i t} \sim \operatorname{IID}\left(0, \sigma_{v}^{2}\right)
$$




$$
\begin{gathered}
\omega_{i}^{2}=\sigma_{\mu_{i}}^{2}=\sigma_{\mu_{i}}^{2}\left(\bar{x}_{i .}\right)=\sigma_{\mu}^{2} \exp \left(\gamma_{\mu} \bar{x}_{i .}\right) \\
\Omega=E\left(\mu \mu^{\prime}\right) \\
=E\left(Z_{\mu} \mu+v\right)\left(Z_{\mu} \mu+v\right) \\
=E\left(Z_{\mu} \mu \mu^{\prime} Z_{\mu}^{\prime}+Z_{\mu} \mu v^{\prime}+v \mu^{\prime} Z_{\mu^{\prime}}+v v^{\prime}\right) \\
=Z_{\mu} E\left(\mu v^{\prime}\right) Z_{\mu^{\prime}}+Z_{\mu} E\left(\mu v^{\prime}\right)+E\left(v v^{\prime}\right) Z_{\mu^{\prime}}+E\left(v v^{\prime}\right) \\
=Z_{\mu} \sum_{\mu} Z_{\mu^{\prime}}+0+0+\sigma_{v}^{2} I_{N T} \\
=Z_{\mu} \sum_{\mu} Z_{\mu^{\prime}}+\sigma_{v}^{2} I_{N T} \\
=\sum_{\mu} I_{N} \otimes \bar{J}_{T}+\sigma_{v}^{2} I_{N T} \\
=\operatorname{diag}\left(\omega_{i}^{2}\right) \otimes \bar{J}_{T}+\sigma_{v}^{2} I_{N T} \\
=\operatorname{diag}\left(T \omega_{i}^{2}+\sigma_{r}^{2}\right) \otimes \bar{J}_{T}+\operatorname{diag}\left(\sigma_{r}^{2}\right) \otimes E_{T}
\end{gathered}
$$

where

$$
\phi_{i}=1-\frac{\sigma_{v}}{\tau_{i}} ; X_{i t}^{*}=X_{i t}-\phi_{i} \bar{X}_{i .} ; \tau_{i}=\sqrt{T \omega_{i}^{2}+\sigma_{v}^{2}}
$$

\subsection{Data Generating Scheme and Data Sources}

Data sets play a very significant role in a decision-making situation as potent ingredients in the choice of appropriate decision support system. This study uses simulated data of Rsoftware 3.3.0 version and the appropriate steps and assumptions were adhere to. The design of our Monte Carlo experiments follows closely that of [10] and [19] for panel data, which in turn adapted it from [28] for cross-section data. We generate the exogenous variable $\left(x_{i t}\right)$, using method similar to Nerlove (1971) method. The method was also used by [24] and several others.

$$
y_{i t}=\beta_{0}+\beta_{1} x_{i t}+\mu_{i}+v_{i t} \quad i=1, \ldots, N, \quad t=1, \ldots, T
$$

where

$$
x_{i t}=\omega_{i, t}+0.5 \omega_{i, t-1,}
$$

We generate $\omega_{i, t}$ as iid $\sim N(0,2)$ and parameters $\left(\beta_{0}, \beta_{1}\right)$ are assigned $(10,0.5)$ respectively. We purposedly choose cross-section units as $\mathrm{N}=150,300$ and time periods, $T=5$, 10 , OEHS $=\gamma_{\mu}$ is assigned value $0,1,2,3$. For each scenario, 5000 replication were made. This study employs Monte Carlo experiments to evaluate the performances of some panel data estimators in the presence of OEHS of oneway error component model (ECM). It focuses on random effects models (REM) with 150 and 300 as cross-sectional units $(\mathrm{N})$ and 5 and 10 as time periods $(\mathrm{T})$.

\section{Discussion of Results}

The count of the number of times each estimator in an experiment performed best was taken into consideration. It was observed that PGLS consistently outperformed all other estimators when considering the ABIAS and, similarly, when the RMSE. This result, in its overall best performance, amounted to 186 times. NER closely followed, being the second best estimator. It is observed also that the performance of each estimator considered using ABIAS and RMSE are always or nearly similar, such that ranking each separately will still yield some results. Consequently, the total number of times each estimator performed best follows some pattern (rank).

\section{Conclusion}

This work identified gaps and addressed the methodology for estimating panel data model in the presence of OEHS. Also, panel data model has been shown analytically and empirically, to be more efficient than cross-section and time 
series data. Since heteroscedasticity is a violation which may lead to increase in residual variance of the estimate of specified model; the estimated parameters are biased leading to incorrect and inconsistence conclusion thereby rendering the results of the analysis highly unreliable for meaningful policy making and planning.

\section{Appendix}

Table 1. Absolute bias $\sigma_{v}^{2}=4 N=150 R=5000$.

\begin{tabular}{llllllllll}
\hline \multirow{2}{*}{ T } & $\gamma_{v}=\gamma_{\mu}$ & \multicolumn{2}{l}{ EXPERIMENT } & & & & & \\
\cline { 2 - 9 } & & POLS & BG & WG & AM & SWAR & WALHUS & NER & PGLS \\
\hline \multirow{3}{*}{5} & 0 & 1.25 & 1.07 & 1.52 & 0.00 & 0.09 & 0.05 & 0.47 & 0.42 \\
& 1 & 0.24 & 0.11 & 0.07 & 176.26 & 4.80 & 9.34 & 1.22 & 0.22 \\
& 2 & 0.76 & 0.10 & 0.07 & 167.41 & 5.53 & 10.54 & 1.10 & 0.80 \\
& 3 & 1.27 & 0.21 & 0.07 & 257.67 & 8.21 & 16.62 & 2.10 & 1.21 \\
10 & 0 & 1.19 & 2.66 & 2.67 & 0.92 & 0.96 & 1.00 & 0.94 & 0.44 \\
& 1 & 0.63 & 0.40 & 0.44 & 0.49 & 0.44 & 0.45 & 0.47 & 0.32 \\
& 2 & 0.78 & 0.53 & 0.67 & 0.50 & 0.56 & 0.53 & 0.51 & 0.71 \\
\hline
\end{tabular}

Source: Author

Table 2. Absolute bias $\sigma_{v}^{2}=4 N=300 R=5000$.

\begin{tabular}{|c|c|c|c|c|c|c|c|c|c|}
\hline \multirow{2}{*}{$\mathbf{T}$} & \multirow{2}{*}{$\gamma_{v}=\gamma_{\mu}$} & \multicolumn{8}{|c|}{ EXPERIMENT } \\
\hline & & POLS & BG & WG & AM & SWAR & WALHUS & NER & PGLS \\
\hline \multirow{4}{*}{5} & 0 & 0.52 & 0.13 & 0.20 & 0.15 & 0.15 & 0.15 & 0.15 & 0.04 \\
\hline & 1 & 1.17 & 7.17 & 4.80 & 2.54 & 2.06 & 2.42 & 2.55 & 5.36 \\
\hline & 2 & 1.37 & 9.69 & 7.25 & 2.94 & 3.05 & 3.02 & 3.90 & 8.09 \\
\hline & 3 & 1.65 & 28.90 & 19.22 & 12.56 & 11.07 & 10.78 & 13.94 & 27.03 \\
\hline \multirow{4}{*}{10} & 0 & 0.46 & 0.48 & 0.33 & 0.23 & 0.21 & 0.21 & 0.22 & 0.05 \\
\hline & 1 & 1.29 & 1.38 & 2.12 & 0.06 & 0.01 & 0.08 & 0.19 & 0.05 \\
\hline & 2 & 1.40 & 2.28 & 3.33 & 0.61 & 0.53 & 0.72 & 0.53 & 4.30 \\
\hline & 3 & 2.04 & 5.40 & 8.50 & 2.76 & 2.95 & 3.00 & 2.90 & 15.24 \\
\hline
\end{tabular}

Source: Author

Table 3. Root mean square error $\sigma_{v}^{2}=4 N=150 R=5000$.

\begin{tabular}{llllllllll}
\hline \multirow{2}{*}{ T } & $\boldsymbol{\gamma}$ & \multicolumn{2}{l}{ EXPERIMENT } & & & & \\
\cline { 2 - 9 } & POLS & BG & WG & AM & SWAR & WALHUS & NER & PGLS \\
\hline & 0 & 1.25 & 1.07 & 1.52 & 0.04 & 0.10 & 0.06 & 0.50 & 0.42 \\
5 & 1 & 0.25 & 0.12 & 0.08 & 11.18 & 4.30 & 6.94 & 1.17 & 0.22 \\
& 2 & 0.76 & 0.11 & 0.07 & 10.61 & 4.98 & 7.82 & 1.05 \\
& 3 & 1.27 & 0.22 & 0.07 & 16.33 & 7.36 & 12.34 & 2.80 \\
& 0 & 1.21 & 2.66 & 2.67 & 0.92 & 0.96 & 1.00 & 0.94 & 0.44 \\
10 & 1 & 0.63 & 0.40 & 0.44 & 0.49 & 0.44 & 0.45 & 0.47 & 0.32 \\
& 2 & 0.77 & 0.53 & 0.67 & 0.50 & 0.55 & 0.53 & 0.51 & 0.71 \\
& 3 & 1.19 & 1.03 & 1.02 & 0.93 & 0.98 & 0.91 & 0.95 & 1.15 \\
\hline
\end{tabular}

Source: Author

Table 4. Root mean square error $\sigma_{v}^{2}=4 N=300 R=5000$.

\begin{tabular}{llllllllll}
\hline \multirow{2}{*}{ T } & $\boldsymbol{\gamma}$ & \multicolumn{2}{l}{ EXPERIMENT } & & & & \\
\cline { 2 - 9 } & & POLS & BG & WG & AM & SWAR & WALHUS & NER & PGLS \\
\hline & 0 & 0.52 & 0.13 & 0.20 & 0.15 & 0.15 & 0.15 & 0.15 & 0.04 \\
5 & 1 & 1.17 & 7.17 & 4.80 & 2.54 & 2.07 & 2.42 & 2.55 & 5.37 \\
& 2 & 1.37 & 9.69 & 7.25 & 2.94 & 3.05 & 3.02 & 3.90 & 8.10 \\
& 3 & 1.65 & 28.88 & 19.24 & 12.56 & 11.07 & 10.78 & 13.97 & 27.04 \\
& 0 & 0.46 & 0.48 & 0.33 & 0.23 & 0.21 & 0.21 & 0.22 & 0.05 \\
10 & 1 & 1.29 & 1.38 & 2.12 & 0.06 & 0.01 & 0.08 & 0.19 & 0.05 \\
& 2 & 1.40 & 2.28 & 3.32 & 0.61 & 0.53 & 0.72 & 0.53 & 4.30 \\
& 2.04 & 5.40 & 8.50 & 2.76 & 2.95 & 3.00 & 2.90 & 15.25 \\
\hline
\end{tabular}

Source: Author 
Table 5. Absolute bias $\sigma_{v}^{2}=8 N=150 R=5000$.

\begin{tabular}{llllllllll}
\hline \multirow{2}{*}{ T } & $\boldsymbol{\gamma}$ & \multicolumn{2}{l}{ EXPERIMENT } & & & & & \\
\cline { 2 - 10 } & & POLS & BG & WG & AM & SWAR & WALHUS & NER & PGLS \\
\hline & 0 & 0.54 & 0.55 & 0.44 & 0.02 & 0.22 & 0.22 & 0.04 & 0.01 \\
5 & 1 & 0.95 & 0.88 & 1.01 & 5.62 & 1.00 & 1.00 & 0.33 & 7.66 \\
& 2 & 0.15 & 0.89 & 1.47 & 34.18 & 2.32 & 2.40 & 12.86 & 47.50 \\
& 3 & 1.06 & 8.12 & 10.28 & 230.69 & 18.04 & 17.79 & 105.66 & 283.85 \\
& 0 & 0.54 & 0.64 & 0.63 & 0.01 & 4.03 & 3.97 & 0.05 & 0.01 \\
10 & 1 & 0.92 & 0.90 & 0.94 & 0.01 & 0.01 & 0.00 & 0.46 & 2.80 \\
& 2 & 0.74 & 0.79 & 1.20 & 1.22 & 0.02 & 0.03 & 1.01 & 15.45 \\
& 3 & 0.46 & 4.83 & 5.30 & 11.96 & 0.15 & 0.16 & 1.29 & 14.06 \\
\hline
\end{tabular}

Source: Author

Table 6. Absolute bias $\sigma_{v}^{2}=8 N=300 R=5000$.

\begin{tabular}{|c|c|c|c|c|c|c|c|c|c|}
\hline \multirow{2}{*}{$\mathbf{T}$} & \multirow{2}{*}{$\gamma$} & \multicolumn{8}{|c|}{ EXPERIMENT } \\
\hline & & POLS & BG & WG & $\mathbf{A M}$ & SWAR & WALHUS & NER & PGLS \\
\hline \multirow{4}{*}{5} & 0 & 0.56 & 0.52 & 0.49 & 0.03 & 0.01 & 0.04 & 0.04 & 0.08 \\
\hline & 1 & 0.98 & 1.09 & 1.29 & 2.23 & 13.58 & 1.31 & 2.28 & 0.54 \\
\hline & 2 & 0.98 & 2.44 & 2.59 & 8.73 & 35.98 & 5.49 & 6.26 & 2.19 \\
\hline & 3 & 1.78 & 8.22 & 9.00 & 62.74 & 272.35 & 38.27 & 53.90 & 13.25 \\
\hline \multirow{4}{*}{10} & 0 & 0.54 & 0.51 & 0.49 & 0.01 & 1.55 & 1.61 & 0.01 & 0.06 \\
\hline & 1 & 0.87 & 0.43 & 0.40 & 11.15 & 0.09 & 0.09 & 17.81 & 0.01 \\
\hline & 2 & 1.10 & 2.26 & 2.41 & 11.84 & 0.13 & 0.09 & 26.70 & 3.51 \\
\hline & 3 & 1.60 & 5.44 & 5.69 & 45.70 & 0.44 & 0.38 & 91.04 & 17.19 \\
\hline
\end{tabular}

Source: Author

Table 7. Root mean square error $\sigma_{v}^{2}=8 N=150 R=5000$.

\begin{tabular}{|c|c|c|c|c|c|c|c|c|c|}
\hline \multirow{2}{*}{$\mathbf{T}$} & \multirow[b]{2}{*}{$\gamma$} & \multicolumn{8}{|c|}{ EXPERIMENT } \\
\hline & & POLS & BG & WG & $\mathbf{A M}$ & SWAR & WALHUS & NER & PGLS \\
\hline \multirow{4}{*}{5} & 0 & 0.54 & 0.55 & 0.44 & 0.02 & 0.22 & 0.22 & 0.04 & 0.01 \\
\hline & 1 & 0.94 & 0.88 & 1.01 & 5.62 & 1.00 & 1.00 & 0.33 & 7.67 \\
\hline & 2 & 0.16 & 0.89 & 1.47 & 34.19 & 2.32 & 2.40 & 12.83 & 47.51 \\
\hline & 3 & 1.10 & 8.12 & 10.31 & 230.73 & 18.05 & 17.80 & 105.43 & 283.94 \\
\hline \multirow{4}{*}{10} & 0 & 0.54 & 0.64 & 0.63 & 0.01 & 4.03 & 3.97 & 0.05 & 0.01 \\
\hline & 1 & 0.92 & 0.90 & 0.94 & 0.02 & 0.01 & 0.00 & 0.46 & 2.72 \\
\hline & 2 & 0.74 & 0.80 & 1.20 & 1.22 & 0.02 & 0.03 & 1.01 & 15.00 \\
\hline & 3 & 0.47 & 4.85 & 5.30 & 11.96 & 0.15 & 0.16 & 1.29 & 13.65 \\
\hline
\end{tabular}

Source: Author

Table 8. Root mean square error $\sigma_{v}^{2}=8 N=300 R=5000$.

\begin{tabular}{|c|c|c|c|c|c|c|c|c|c|}
\hline \multirow[b]{2}{*}{$T$} & \multirow[b]{2}{*}{$\gamma$} & \multicolumn{8}{|c|}{ EXPERIMENT } \\
\hline & & POLS & BG & WG & $\mathbf{A M}$ & SWAR & WALHUS & NER & PGLS \\
\hline \multirow{4}{*}{5} & 0 & 0.56 & 0.52 & 0.49 & 0.03 & 0.01 & 0.04 & 0.04 & 0.08 \\
\hline & 1 & 0.98 & 1.09 & 1.29 & 2.21 & 13.58 & 1.31 & 2.28 & 0.55 \\
\hline & 2 & 0.98 & 2.44 & 2.59 & 8.68 & 36.00 & 5.47 & 6.26 & 2.19 \\
\hline & 3 & 1.82 & 8.22 & 9.00 & 62.31 & 272.44 & 38.19 & 53.77 & 13.25 \\
\hline \multirow{4}{*}{10} & 0 & 0.54 & 0.51 & 0.49 & 0.01 & 1.55 & 1.61 & 0.01 & 0.06 \\
\hline & 1 & 0.87 & 0.43 & 0.40 & 11.15 & 0.09 & 0.09 & 17.81 & 0.01 \\
\hline & 2 & 1.10 & 2.27 & 2.41 & 11.86 & 0.13 & 0.09 & 26.71 & 3.51 \\
\hline & 3 & 1.60 & 5.45 & 5.69 & 45.71 & 0.44 & 0.38 & 91.05 & 17.19 \\
\hline
\end{tabular}

Source: Author

\section{References}

[1] Hsiao, C. (2003), Analysis of Panel Data. Second Edition, Cambridge University Press. Cambridge.

[2] Baltagi, B. H. (2005), Econometric Analysis of Panel Data, 5thEdition Wiley, Chichester.

[3] Baltagi, B. H. (2008), Econometric Analysis of Panel Data, 6thEdition, Wiley, Chichester.
[4] Mazodier, P. and A. Trognon (1978), Heteroscedasticity and stratification in error components models, Annales de l'INSEE 30-31, 451-482.

[5] Rao, S. R. S., J. Kaplan, W. C. Cochran (1981), Estimators for the one-way random effects model with unequal error variances, Journal of the American Statistical Association 76, 89-97.

[6] Magnus, J. R. (1982), Multivariate error components analysis of linear and nonlinear regression models by maximum likelihood, Journal of Econometrics 19, 239- 285. 
[7] Baltagi, B. H. and J. M. Griffin (1988a), A generalised error component model with heteroscedastic disturbances, International Economic Review 29, 745-753.

[8] Randolph, W. C. (1988), A transformation for heteroscedastic error components regression models, Economics Letters 27, 349-354.

[9] Wansbeek, T. J. (1989), An alternative heteroscedastic error components model, Econometric Theory 5, 326.

[10] Li, Q. and T. Stengos (1994), Adaptive estimation in the panel data error component model with heteroscedasticity of unknown form, International Economic Review 35, 981-1000.

[11] Balestra, P. and M. Nerlove (1966), Pooling cross-section and time series data in the estimation of a dynamic model: the demand for natural gas, Econometrica 34, 585-612.

[12] Nerlove, M. (1971a), Further evidence on the estimation of dynamic economic relations from a time series of cross sections, Econometrica 39, 359-382.

[13] Maddala, G. S. and T. D. Mount (1973), A comparative study of alternative estimators for variance components models used in econometric applications, Journal Of The American Statistical Association 68, 324-328.

[14] Wallace, T. D. and A. Hussain (1969), The use of error component models in combining cross-section with time series data, Econometrica 37, 55-68.

[15] Amemiya, T. (1971). The estimation of the variances in a variance-components model. International Economic Review 12: 1-13.

[16] Nerlove, M. (1971b), A note on error components models, Econometrica 39, 383-396.

[17] Swamy, P. A. V. B. and S. S. Arora (1972), The exact finite sample properties of the estimators of coefficients in the error components regression models, Econometrica 40, 261-275.

[18] Baltagi, B. H., G. Bresson and A. Pirotte (2005), Adaptive estimation of the heteroscedastic error component model, Econometric Reviews, Volume 24, Issue 1, pages 39-58.
[19] Roy, N. (2002), Is adaptive estimation useful for panel models with heteroscedasticity in the individual specific error component? Some Monte Carlo Evidence, Econometric Reviews 21, 189-203.

[20] Cardellichio, P. A. (1990) "Estimation of Production Behavior Using Pooled Microdata" Review of Economics and Statistics 72, 11-18.

[21] Behrman, J., and A. Deolalikar (1990) The Intrahousehold Demand for Nutrients in Rural South India: Individual Estimates, Fixed Effects and Permanent Income. The Journal of Human Resources 25: 4 665-696.

[22] Green, H. W. (2008). Econometric Analysis (6th ed). Pearson, NJ: Prentice Hall.

[23] Baltagi, B. H., B. C. Jung and S. H. Song (2008), Testing for heteroscedasticity and serial correlation in a random effects panel data model, Working Paper number 111, Syracuse University, USA.

[24] Ayoola, F. J., Olubusoye, O. E. and Salisu, A. A. (2013). Panel Data Estimators in the Presence of Quadratic and Exponential forms of Heteroscedasticity. Journal of Science Research, Vol. 12: 263-274.

[25] Johnson, S. C. and Lahiri, K. Empirical Economics (1992) 17: 141. doi: 10.1007/BF01192480.

[26] Conway, K. S. and Kniesner, T. J., (1992). Estimating the Frisch Labor-Supply Function," Papers 92-015.

[27] Cornwell, C. and Rupert, P. (1997), Unobservable individual effect, marriage and earnings of young men. Economic Inquiry, 35: 285-294. doi: 10.1111/j.14657295.1997.tb01910.x.

[28] Rilstone, P. (1991), Some Monte Carlo evidence on the relative efficiency of parametric and semi-parametric EGLS estimators, Journal of Business and Economic Statistics 9, 179-187.

[29] Kouassi, E. eta'1 (2014), Testing for heteroskedasticity and spatial correlation in a two way random effects model, Computational Statistics \& Data Analysis, Elsevier, vol. 70(C), 153-171. 